\title{
Application of Unmanned Aerial Vehicles for Glacier Research in the Arctic and Antarctic
}

\author{
Kristaps Lamsters \\ Faculty of Geography and Earth Sci- \\ ences \\ University of Latvia \\ Riga, Latvia \\ kristaps.lamsters@gmail.com \\ Jurijs Ješkins \\ Faculty of Geography and Earth Sci- \\ ences \\ University of Latvia \\ Riga, Latvia \\ jurijs.jeshkins@gmail.com
}

\begin{abstract}
Unmanned aerial vehicles or drones are nowadays widely used in a broad field of scientific and commercial applications. Despite this, it is quite a new method for glacier mapping in polar regions and has a lot of advantages, as well as disadvantages over more classical remote sensing instruments. Here we examine the main issues associated with the application of drones for glacier research from our experience in Iceland, Greenland and the Antarctic. We use DJI Phantom series drones for the obtaining of aerial photographs and produce digital surface models (resolution of $8-16 \mathrm{~cm}$ ) and orthomosaics (resolution of $2-4 \mathrm{~cm}$ ) for glacier mapping. Several issues related to the ground control points, geolocation using Global Navigation Satellite System receiers and creation of final products are addressed as well. We recommend the further use of drones in remote polar areas because it allows obtaining very high-resolution orthomosaics and digital surface models that are not achieved by other methods. Short summer season, raw weather with precipitation and winds, limited drone flight duration and problems with connection cables are the main issues everyone can encounter working in polar regions but all issues can be restricted with careful planning and readiness to gather data whenever it is possible during all field campaign.
\end{abstract}

Keywords—drone, digital surface model, orthomosaic, polar regions.

\section{INTRODUCTION}

Nowadays remote sensing is one of the most powerful tools in Earth Sciences and especially in glaciology and glacial geomorphology [1]. Different kinds of sensors and instruments are placed on satellites and aircrafts allowing mapping ice sheets in Greenland and Antarctica. The Randolph Glacier Inventory (RGI) provides a global inventory of glacier outlines [2]. Global Land Ice Measurements from Space project monitors the glaciers over the globe using data from optical satellite instruments [3]. High-resolution digital surface models (DSMs) are available for Antarctica (the Reference Elevation Model of Antarctica (REMA) with 8-meter spatial resolution)

[4] and all the Arctic (the newest ArcticDEM Release 7 includes 2-meter resolution DEM covering all land area north of $60^{\circ}$ and additional areas) [5].

Despite all available data, the mentioned datasets lack the information often needed for the detailed investigations of individual glaciers. To resolve this, unmanned aerial vehicles (UAV) or drones are being used increasingly. Glacier studies with UAVs is a new method [6], but nowadays its applications includes, for example, high-resolution investigation of glacial landforms [7] [11], monitoring of glacier dynamics [12], calving and melting dynamics [13] and [14], identification of surface structures [15] and others.

During the last years, scientists from the University of Latvia have been using drones to map glaciers in Greenland (2016), Iceland (2018) and Antarctica (2018). The focus in these expeditions has been on the generation of high-precision DSMs and models of the subglacial topography from ground penetrating radar data. In this paper, we review our experience, problems, main results and future perspectives of using drones in remote polar regions.

\section{Materials and Methods}

For the capturing of aerial photographs we use drones DJI Phantom 3 advanced (Figs. 1a, b) and DJI Phantom 4 Pro V2.0 (Fig. 1e). These are rotary-wing quadcopters equipped with 1/2.3" CMOS 12.4 Megapixel and 1" CMOS 20 Megapixel sensors accordingly. Usually, two drones are taken to the polar expeditions, one of them serving as a backup. In remote areas, the question of battery charging possibilities arises, because the flight duration with one battery is only around 20 minutes. It was necessary to use a portable current generator during expeditions in Iceland and Greenland. In the Antarctic, the Vernadsky Station was used as a base that allowed 
charging of batteries. On the expedition in Iceland, we used DJI Mavic Air (Fig. 1c) as a reserve in case of possible technical problems with the main drone. Mavic Air is so small that it fits in a pocket. In that way, it is so easy to transport it but because of the good operation of the main drone, we have used it only for photo and video background. Few studies [16] and [17] and our experience outside polar regions suggest that it is possible to use small DJI Mavic Air also for photogrammetry although due to several issues Phantom is recommended instead.
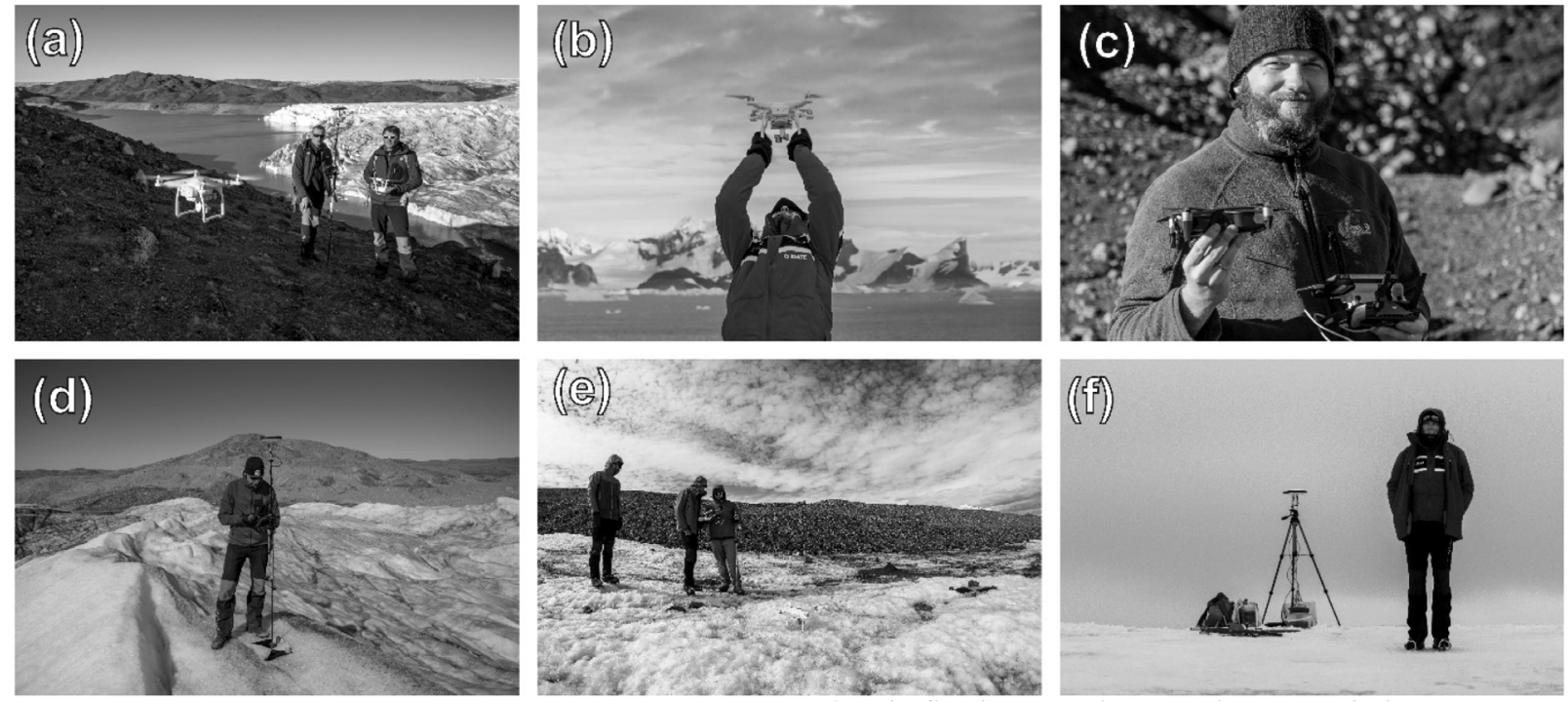

Fig. 1. (a) Using the drone DJI Phantom 3 Advanced in Greenland. (b) Hand catching of the drone DJI Phantom 3 Advanced in the Antarctic. (c) Operating one of smallest drones DJI Mavic Air in Iceland as a backup drone. (d) Measuring the GCP with Magellan Promark 3 GPS receiver in Greenland. (e) Operating the drone DJI Phantom 4 Pro v2.0 in Iceland. (f) Improvised GPS base station in the Antarctic using Magellan Promark 3 GPS system.

The control of drone and mission generation has been done by DJI GO 4, Drone Harmony and Pix4Dcapture mobile applications which are available for free or acceptable fee.

Flight altitude most frequently was set to $60-70 \mathrm{~m}$ over the take-off point which usually is at the highest elevation while image overlap was set to $80-85 \%$. The accuracy requirements of DSMs are ensured using

ground control points (GCPs). In the first expeditions, we used GCPs from a firm plastic material with dimensions of $35 \times 35 \mathrm{~cm}$ (Fig. 2b), while for the last expedition to Iceland larger $(50 \times 50 \mathrm{~cm})$ GCPs that were made from a flexible fabric material were used (Fig. 2a). Different issues are related to both kinds of GCPs. Rocks which are used to secure GCPs on the ice can slip from the GCP made from the firm plastic material due to the fast melting of the surrounding ice (Fig. 2b). GCPs from the flexible fabric material (Fig. 2a) are harder to stretch evenly over the ice surface but overall such kind of GCPs is more preferable over inflexible GCPs.

Flexible GCPs are easier to transport to the survey territories, as well as they are much lighter. Bright colours of the fabric can be easily identified on the UAV pictures. Overall we use $10-15$ GCPs on the area for one mission. For georeferencing purposes, only 7-9 GCPs are used, while other GCPs are useful for validation of the photogrammetric model.

UAV GCPs are measured with GNSS receivers Magellan Promark 3 (Fig. 1d) or Emlid Reach RS+. The measurement system consists of two GNSS receivers one is used as a base station, but the second as a rover. A base station is usually placed at the highest elevation of the survey territory (Fig. 1f), and the log file is

continuously recorded during the day as long as possible. Post-processing is done with
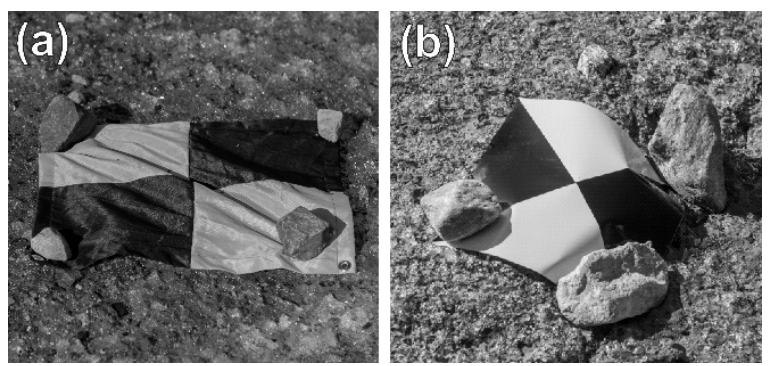

Fig. 2. Examples of used GCPs with dimensions of (a) $50 \times 50 \mathrm{~cm}$ and (b) $35 \times 35 \mathrm{~cm}$.

GNSS solutions software [18] if Magellan Promark 3 is used or with RTKlib solution [19] if Emlid Reach $\mathrm{RS}+$ is used. Base station location is always determined using GNSS signal corrections from the closest GNSS station, which is usually located several tens of kilometres away from the study area. While processing data from the Antarctic expedition we used signal corrections from the closest GNSS station "Palmer" that was located approximately $53 \mathrm{~km}$ away from the study area. It is not recommended to use base stations that are located more than $40 \mathrm{~km}$ away from the survey territory but in this case, it was the only opportunity and it allowed obtaining base station coordinates with a deviation of approximately 4 $\mathrm{cm}$ in all cases. Longer observation times of the local base station can improve the results of the positioning but require an additional power supply for the GNSS receiver.

Obtained aerial images allow the creation of orthomosaics with a resolution of $2-4$ centimetres and DSMs with a resolution around $8-16$ centimetres using photogrammetry processes in Agisoft PhotoScan Pro and Metashape software. Processing workflow and 
parameters are set according to Agisoft guidelines [20] and our experience. As the number of images is usually larger than 1000, and often reaches several thousand, a workstation with a high-performance graphics card, fast multiprocessors and large RAM size is needed.

Photogrammetry processes in Agisoft software include the following steps:

- Camera alignment and generation of a sparse cloud;

- Generation of DSM and orthomosaic from the sparse cloud;

- Selection of the GCPs and assignment of the corrected coordinates;

- Optimization of cameras;

- Generation of Dense cloud;

- Generation of final DSM;

- Generation of final orthomosaic.
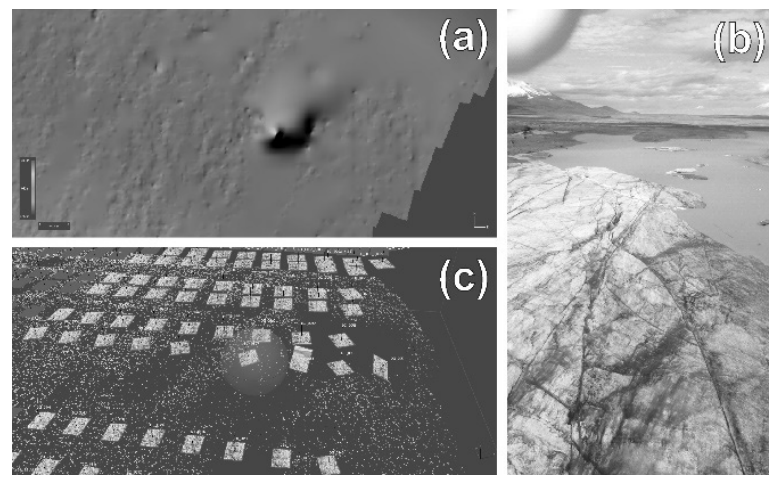

Fig. 3. (a) Sharp uplift in DSM of the Eyjabakkajökull glacier, Iceland. (b) An oblique photograph of the glacier margin causing an error in dense cloud and DSM. (c) Dense cloud with the oblique photograph.

\section{Results And Discussion}

A number of issues can be encountered during the capture of aerial photographs with UAV during polar expeditions. Smallest of them are damaged and wearied out connection cables. Problems with cables can occur even when they are completely new. Incomprehensible problems sometimes are associated with aircraft and remote controller connections, signal loss or application support. The main issues in Polar Regions are bad weather, usually precipitation and fog, coldness and strong wind. Too low drone and/or battery temperature can cause drone failure although usually cold batteries can be warmed up by the heat of the human body. Strong and sudden wind gusts are particularly troublesome and can cause the taking of oblique photographs (Figs. 3b, c). If all photographs, including oblique ones, are used later for photogrammetry, it can create errors in dense clouds and surface models as sharp uplifts (Fig. 3a). Of course, blurred and oblique images can be easily disabled during photogrammetry processes although sometimes it must be done manually, it can cause the shortage of images in places decreasing accuracy of the final model. An essential issue in the Antarctic and the high Arctic as well, is a short summer season. As orthomosaics and DSMs in glaciology are used for the monitoring of glacier area and elevation changes, it is usually important to take pictures when there is minimal snow cover over glaciers. The time spans when weather conditions are suitable for the UAV flights can be very limited. During our Antarctic expedition (2018) almost all flights over the Argentine Islands of the Wilhelm Archipelago were performed in February. In March, snowing was quite common thereby few islands in obtained orthomosaics were partially covered by snow. This caused local errors on DSMs, usually on the highest parts of ice caps where the surface was too evenly white.

Photogrammetry process results in several final products that can be used for the following interpretation and research. DSMs and orthomosaics are used more often but from the same picture set it is possible obtaining point clouds and 3D models (Fig. 4). The quality of these products depends on the camera system that is being used on the UAV, as well as the UAV survey parameters - flight altitude, an overlap between pictures, picture resolution, etc. For our purposes resolution of the DSMs around $10 \mathrm{~cm} / \mathrm{px}$ is enough for most applications, while the resolution of the final orthomosaics is around $3 \mathrm{~cm} /$ px. These attributes of the DSMs and orthomosaics allow to interpret the surface of the glaciers and to map such small features as crevasses, crevasse traces, moulins, and supraglacial streams, which are not visible even on DSMs created from $0.5 \mathrm{~m}$ satellite imagery as, for example, ArcticDEM with 2-meter resolution [5]. The obtained DSMs then are used in combination with ice thickness measurements from ground penetrating radar that allows the creation of subglacial topography models.

Our studies show that it is crucial to take pictures in RAW format, rather than in JPEG despite of a few times larger file size. The RAW format gives more flexibility in the post-processing of the obtained pictures. Polar region areas usually consist out of glacierized and snowy areas that are very bright on the pictures, and rocky regions on the other hand that are much darker. Both types of areas require different exposition settings. RAW format allows making corrections of exposure parameters in postprocessing, thus allowing to take pictures with locked exposition parameters and making corrections afterward.

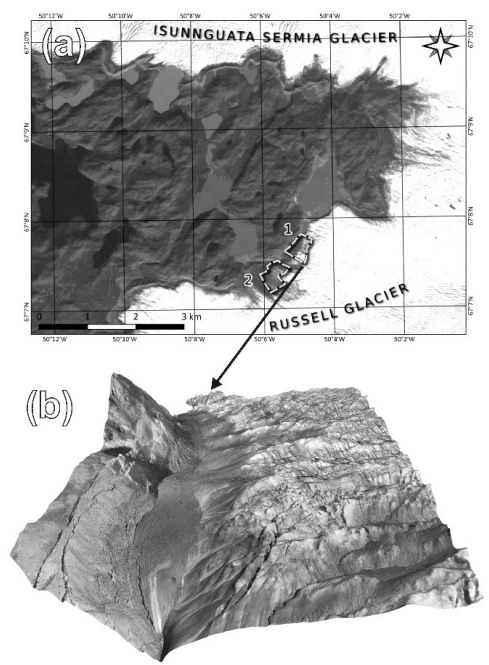

Fig. 4. (a) An example of the study areas (1 and 2) in the SW Greenland. Sentinel satellite image a the background. (b) 3D model of the glacier margin from UAV photogrammetry (orthomosaic draped over DEM). 
Photogrammetry process can yield errors in DSM [21]. Our experiments show that results of the same photogrammetry set processed on different PCs or even repeatedly on the same PC can produce different models because of the random factor that is involved in the alignment of the picture set. Deviations in the model can be as high as $20 \mathrm{~cm}$ on a vertical scale and even larger on a horizontal plane. Some of these errors can be analysed visually, while some require another identification approach. We use additional GCPs for validation of the model that were not used in the alignment of the pictures. Fresh snow on the glacier surface can drastically increase the possibility of these errors, because of the strong reflections of the sunlight. Manual post-processing of the pictures often helps to reduce reflections.

\section{CONCLUSIONS}

Our work in Iceland, Greenland and the Antarctic has demonstrated that the application of small drones in glaciology nowadays is an affordable and accurate method for the construction of high-resolution orthomosaics and digital surface models. Fast data acquisition and flexibility of flights opens new opportunities for glaciological mapping including remote regions where it is not possible to use other mapping methods. Automatic mission's option allows planning flight routes while still being in a camp, thus bearing in mind possible issues and errors. The small size of UAVs allows easier transportation to the study area.

Applications of UAVs in the remote polar regions still have few limitations, particularly short flight duration. Issues related to weather conditions always is a matter of chance but the newest technologies, even in small and affordable Phantom series drones, provide good weather sealing and camera stabilization allowing the taking of pictures even in damp and windy conditions. However, strong and sudden wind gusts can cause taking of oblique images or even deviation from the flight route thus forcing to repeat the mission.

With the advance of UAV technologies, it will be possible to use other sensors as well and acquiring broad spectre of spatial data. We recommend the further use of drones in remote polar areas because it allows obtaining very high-resolution orthomosaics and digital surface models that are not achievable by other methods.

\section{ACKNOWLEDGMENTS}

This work was supported by the performance-based funding of University of Latvia within the "Climate change and sustainable use of natural resources" and by the specific support objective activity 1.1.1.2. "Post-doctoral Research Aid" (Project id. 1.1.1.2/16/I/001) of the Republic of Latvia, funded by the European Regional Development Fund, Kristaps Lamsters research Project No. 1.1.1.2/VIAA/1/16/118.

\section{REFERENCES}

[1] C. Porter, P. Morin, I. Howat, M-J. Noh, B. Bates, K. Peterman, S. Keesey, M. Schlenk, J. Gardiner, K. Tomko, M. Willis, C. Kelleher, M. Cloutier, E. Husby, S. Foga, H. Nakamura, M. Platson, M. Wethington, C. Williamson, G. Bauer, J. Enos, G. Arnold, W. Kramer, P. Becker, A. Doshi, C. D'Souza, P. Cummens, F. Laurier, and M. Bojesen, "ArcticDEM", March 2018. [online] Available: https://dataverse.harvard.edu/dataset. xhtml?persistentId=doi:10.7910/DVN/OHHUKH [Accessed: March 31, 2019], https://doi.org/10.7910/DVN/OHHUKH

[2] A. Finlayson, E. Phillips, Í. Ö. Benediktsson, L. K., Zoet, N. R. Iverson, and J. Everest, "Subglacial drumlins and englacial fractures at the surge-type glacier, Múlajökull, Iceland," Earth Surface Processes and Landforms, vol. 44, no. 1, pp. 367-380, August 2018, https://doi.org/10.1002/esp.4485

[3] Takasu, T. RTKLIB: Open Source Program Package for RTKGPS: FOSS4G 2009, November 2, 2009, Tokyo, Japan. [online] Available: http://gpspp.sakura.ne.jp/paper2005/ foss4g_2009_rtklib.pdf [Accessed: December 31, 2018].

[4] "Agisoft Metashape User Manual: Professional Edition, Version 1.5.” 2018. [online]. Available: https://www.agisoft.com/pdf/ metashape-pro 1 5 en.pdf [Accessed: March 25, 2019].

[5] P. Pellikka and W. G. Rees, Remote Sensing of Glaciers: Techniques for Topographic, Spatial and Thematic Mapping of Glaciers. London, UK: Taylor \& Francis Goup, 2010.

[6] RGI Consortium, "Randolph Glacier Inventory - A Dataset of Global Glacier Outlines: Version 6.0," Global Land Ice Measurements from Space, Colorado, USA, Tech. Rep., 2017, https://doi.org/10.7265/N5-RGI-60

[7] B. M. P. Chandler, D. J. A. Evans, D. H. Roberts, M. Ewertowski, and A. I. Clayton, "Glacial geomorphology of the Skálafellsjökull foreland, Iceland: A case study of 'annual' moraines," Journal of Maps, vol. 12, no. 5, pp. 904-916, 2016, http://dx.doi.org/10.108 0/17445647.2015.1096216

[8] "GLIMS: Global Land Ice Measurements from Space," 2005. [Online]. Available: https://www.glims.org/ [Accessed: March 20, 2019], http://dx.doi.org/10.7265/N5V98602

[9] I. Howat, P. Morin, C. Porter, M. J. Noh, "The Reference Elevation Model of Antarctica," 2018. [Online] Available: https://dataverse. harvard.edu/dataset.xhtml?persistentId=doi:10.7910/DVN/ SAIK8B. [Accessed: Jan. 10, 2019], V1, https://doi.org/10.7910/ DVN/SAIK8B

[10] W. W. Immerzeel, P. D. A. Kraaijenbrink, J. M. Shea, A. B. Shrestha, F. Pellicciotti, M. F. P. Bierkens, and S. M. De Jong, "High-resolution monitoring of Himalayan glacier dynamics using unmanned aerial vehicles," Remote Sensing Environment, vol. 150, pp. 93-103, July 2014, https://doi.org/10.1016/j. rse.2014.04.025

[11] A. Bhardwaj, L. Sam, F.J. Martín-Torres, and R. Kumar, "UAVs as remote sensing platform in glaciology: Present applications and future prospects," Remote sensing of environment, vol. 175, pp. 196-204, March 2016, https://doi.org/10.1016/j.rse.2015.12.029

[12] J. C. Ely, C. Graham, I. D. Barr, B. R. Rea, M. Spagnolo, and J. Evans, "Using UAV acquired photography and structure from motion techniques for studying glacier landforms: application to the glacial flutes at Isfallsglaciären," Earth Surface Processes and Landforms, vol. 42, no. 6, pp. 877-888, Sept 2017, https://doi. org/10.1002/esp.4044

[13] M. W. Ewertowski, D. J. A. Evans, D. H. Roberts, and A. M. Tomczyk, "Glacial geomorphology of the terrestrial margins of the tidewater glacier, Nordenskiöldbreen, Svalbard," Journal of Maps, vol. 12, sup1, pp. 476-487, 2016, https://doi.org/10.1080 /17445647.2016.1192329

[14] N. G. Midgley, T. N. Tonkin, D. J. Graham, and S. J. Cook, "Evolution of high-Arctic glacial landforms during deglaciation," Geomorphology, vol. 311, pp. 63-75, June 2018, https://doi. org/10.1016/j.geomorph.2018.03.027

[15] T. N. Tonkin, N. G. Midgley, S. J. Cook, and D. J. Graham, "Ice-cored moraine degradation mapped and quantified using an unmanned aerial vehicle: a case study from a polythermal glacier in Svalbard," Geomorphology, vol. 258, pp. 1-10, April 2016, https://doi.org/10.1016/j.geomorph.2015.12.019

[16] M. Rossini, B. Di Mauro, R. Garzonio, G. Baccolo, G. Cavallini, M. Mattavelli, M. De Amicis, and R. Colombo, "Rapid melting dynamics of an alpine glacier with repeated UAV photogrammetry," Geomorphology, vol. 304, pp. 159-172, March 
Environment. Technology. Resources. Rezekne, Latvia Proceedings of the 12th International Scientific and Practical Conference. Volume I, 131-135

2018, https://doi.org/10.1016/j.geomorph.2017.12.039

[17] J. C. Ryan, A. L. Hubbard, J. E. Box, J. Todd, P. Christoffersen, J. R. Carr, T. O. Holt, and N. Snooke, "UAV photogrammetry and structure from motion to assess calving dynamics at Store Glacier, a large outlet draining the Greenland ice sheet," Cryosphere, vol. 9, no. 1, pp. 1-11, Jan. 2015, https://doi.org/10.5194/tc-9-1-2015

[18] "GNSS solutions reference manual" 2012. [Online]. Available: https://ashgps.com/2/GNSS\%20Solutions/manuals/English/ GNSSSolutions_RM_F_en.pdf [Accessed: December 25, 2018].

[19] P. Burdziakowski, UAV in today's photogrammetry - application areas and challenges. Photogrammetry and Remote Sensing: $18^{\text {th }}$
International Multidisciplinary Scientific GeoConference SGEM 2018, August 24 - September 2, 2018, Albena, Bulgaria.

[20] P.J. Hardin, V. Lulla, R.R. Jensen, and J.R. Jensen, "Small Unmanned Aerial Systems (sUAS) for environmental remote sensing: challenges and opportunities revised," GIScience \& Remote Sensing, vol. 56, no. 2, pp. 309-322, 2018. https://doi.org $110.1080 / 15481603.2018 .1510088$

[21] M.R. James, and S. Robson, "Mitigating systematic error in topographic models derived from UAV and ground-based image networks," Earth Surface Processes and Landforms, vol. 39, no. 10, pp. 1413-1420, May 2014, https://doi.org/doi:10.1002/ esp.3609 